
67 巻 656 号 $(2001-4)$

\title{
鞭毛を模擬した小型ポンプ，小型粘度計*
}

\author{
砂田茂*1, 信 賀 信 孝*2, 安田邦男*3 \\ 尾崎 浩 一*1, 田中誠*1
}

\section{A Millimeter-Sized, Helical-Wire Pump that is also a Viscometer}

\author{
Shigeru SUNADA**, Nobutaka SHINGA, Kunio YASUDA, \\ Koichi OZAKI and Makoto TANAKA \\ *4 National Institute of Aduvanced Industrial Science and Technology, \\ 1-2 Namiki, Tsukuba-shi, Ibaraki, 305-8564 Japan
}

\begin{abstract}
A small pump (about $10 \mathrm{~mm}$ on a side) with a rotating helical wire was developed. Hydrodynamic forces generated by the small pump were measured by varying the rotational speed of the helical wire and by varying the fluid viscosity. The measured hydrodynamic forces agree well with those predicted by using the resitive theory based on the hydrodynamics of flow at a low Reynolds number. The measured hydrodynamic forces generated by the pump were proportional to the rotational speed of the helical wire. This suggests that the small pump can be used to control hydrodynamic forces with high accuracy. Furthermore, the hydrodynamic force generated by the pump was also proportional to the fluid viscosity. This suggests that this pump is also a small viscometer.
\end{abstract}

Key Words : Helical Wire, Flagellar Hydrodynamics, Small Pump, Small Viscometer, Resistive Force Theory

\section{1. 緒蒡}

微量な流体の取り扱い、狭い空間での使用、軽量化 を目的として、流体機器の小型化に対する要求が高 まっている。流体機器を小型化するとレイノルズ数 $R_{e}$ が低下するが、 $R_{e}$ の大きさによって物体に働く流 体力の特性が大きく変化する(1)。よって、流体機器 の小型化にあたっては、従来の大型流体機器を、その まま小さくしても高い性能を得ることはできない。

高い性能を有する流体機器を開発するにあたっては、 生物の推進機器が永い自然淘汰の結果それぞれの璒境 下で最適化され高い性能を有する(2)ことを利用し、 生物の推進器を模擬するという方法がある (3)。小型 の生物の推進器には鞭毛によって推進する生物が多い ので、鞭毛を模擬した小型ポンプ、小型粘度計を試作

* 原稿受付 2000 年 8 月 2 日.

*1 正員, 独立行政法人産業技術総合研究所つくば東事業所人間 福祉医工学研究部門 (恶305-8564 つくば市並木 1-2-1).

*2 日本大学大学院 (画 274-8501 船橋市習志野台 7-24-1).

*3 正員, 日本大学理工学部.

E-mail : sunada.s@ aist.go.jp
し、その性能評価を行った。

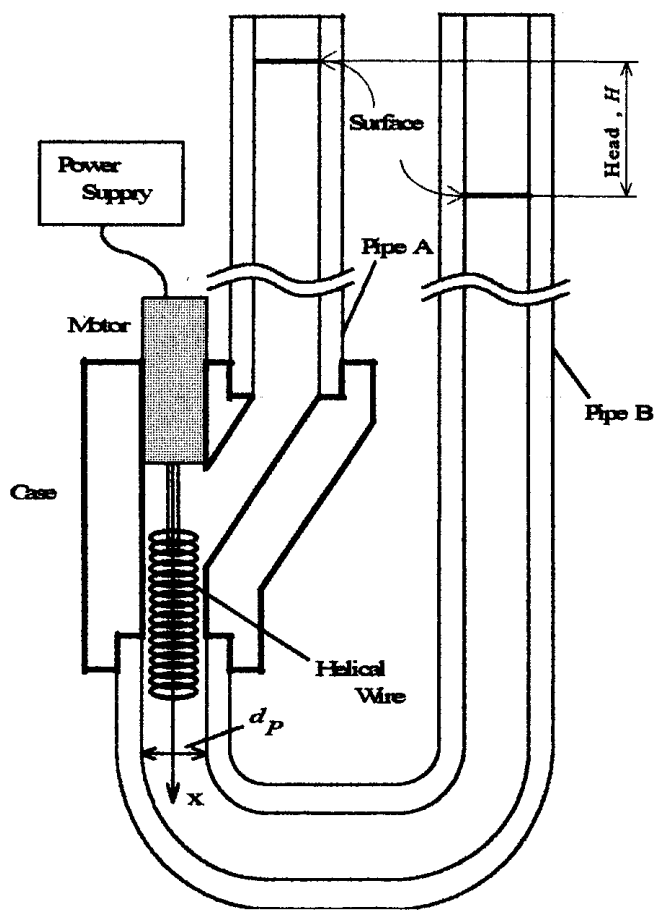

Fig.1 Experimental apparatus. 


\section{2、実験装置および実験方法}

図1に、本研究で使用した実験装置を示す。内径が $d_{p}=2 \times 10^{-5} \mathrm{~m}$ のパイプA、B間にシリコンオイル が満たされている。シリコンオイルの密度は $\rho=975 \mathrm{~kg} / \mathrm{m}^{3}$ 、動粘性係数は $v=100 \mathrm{~mm}^{2} / \mathrm{s}$ または $v=300 \mathrm{~mm}^{2} / \mathrm{s}$ または $v=1000 \mathrm{~mm}^{2} / \mathrm{s}$ の 3 種類であ る。パイプ A、パイプ B は、それぞれY字型管路の口 につながれ、Y字型管路の残りの口には直径が

$1.9 \mathrm{~mm}$ のモータ（スイス・ミニモータ社製、マイク ロドライブシステム) が挿入されている。モータの回 転軸（直径： $0.24 \mathrm{~mm}$ ）にステンレス製の螺旋の一端 が巻き付くことで、モータと螺旋はつながっている。 図 2および表 1に、蠌旋のサイズを示す。

Table 1 Size of a helical wire and pipes

\begin{tabular}{|lll|}
\hline Items & Abbreviation & Values \\
\hline Diameter of a wire & $d_{H}$ & $0.2 \mathrm{~mm}$ \\
\hline Radius of helix & $a$ & $0.35 \mathrm{~mm}$ \\
\hline Wave length & $\lambda$ & $0.75 \mathrm{~mm}$ \\
\hline & $2 \pi a / \lambda$ & 2.9 \\
\hline & $d_{H} / \lambda$ & 0.27 \\
\hline Diameter of pipes & $d_{P}$ & $2 \mathrm{~mm}$ \\
\hline & $d_{P} / \lambda$ & 2.7 \\
\hline
\end{tabular}

螺旋の巻き方向は、螺旋の軸（ $\mathrm{x}$ 軸）に沿って時計回 りである。螺旋はモータにより回転数 $f$

$(-50 \mathrm{~Hz}<f<50 \mathrm{~Hz})$ で回転するが、回転の正方向 は $\mathrm{x}$ 軸に沿って時計回りとする。負の回転数 $f$ は、 $\mathrm{x}$ 軸に沿って反時計回りに回転数 $|f|$ で回転することを 意味する。
回転螺旋が発生する推力により、パイプ A、B の液端 面に高さの差（ヘッド $H ）$ が生じるが、その值を測 定した。動粘性係数が $v=100 \mathrm{~mm}^{2} / \mathrm{s}$ のシリコンオ イルについては $L=8 \mathrm{~mm}$ または $L=24 \mathrm{~mm}$ で、動粘 性係数が $v=300,1000 \mathrm{~mm}^{2} / \mathrm{s}$ のシリコンオイルにつ いては $L=8 \mathrm{~mm}$ で測定を行った。

\section{3. 解析}

細菌の運動の解析において用いられる、低レイノル ズ数におおける抵抗力理論 (4)にもとづいた解析を行う。 本解析に㧈いては、以下の 3 つの仮定を前提にする。

（仮定 I）螺旋は流体力、慣性力によって変形しない。 （仮定 II）螺旋各部位の流体力学的干渉を無視する。 (仮定而) 螺旋とパイプとの流体力学的干涉を無視す る。

螺旋の発生する推力

図 2 に示す螺旋が回転する時に発生する推力 $T$ は、 レイノルズ数 $R_{e}$ が 1 以下、すなわち、

$$
R_{e}=\frac{2 \pi|f| a d_{H}}{v}<1
$$

$\left(f\right.$ : 螺㳬の回転数、 $a$ : 螺旋の半径、 $d_{H}$ : 線径、 $v$ : 流体の動粘性係数) である時、抵抗力理論を用い て以下の様に求められる。螺旋の線素 $d s$ に働く流体 力の線素に垂直な成分 $d D_{N}$ 、平行な成分 $d D_{T}$ はそれ ぞれ、

$d D_{N}=C_{N}(2 \pi a f) \cos \Theta d s, d D_{T}=-C_{T}(2 \pi a f) \sin \Theta d s$

で与えられる。ここで、 $\Theta=\tan ^{-1}\{a(2 \pi / \lambda)\}$ であり、 $C_{N} 、 C_{T}$ は流体力係数で、線径 $d_{\mathrm{H}}$ 、流体の粘性保数

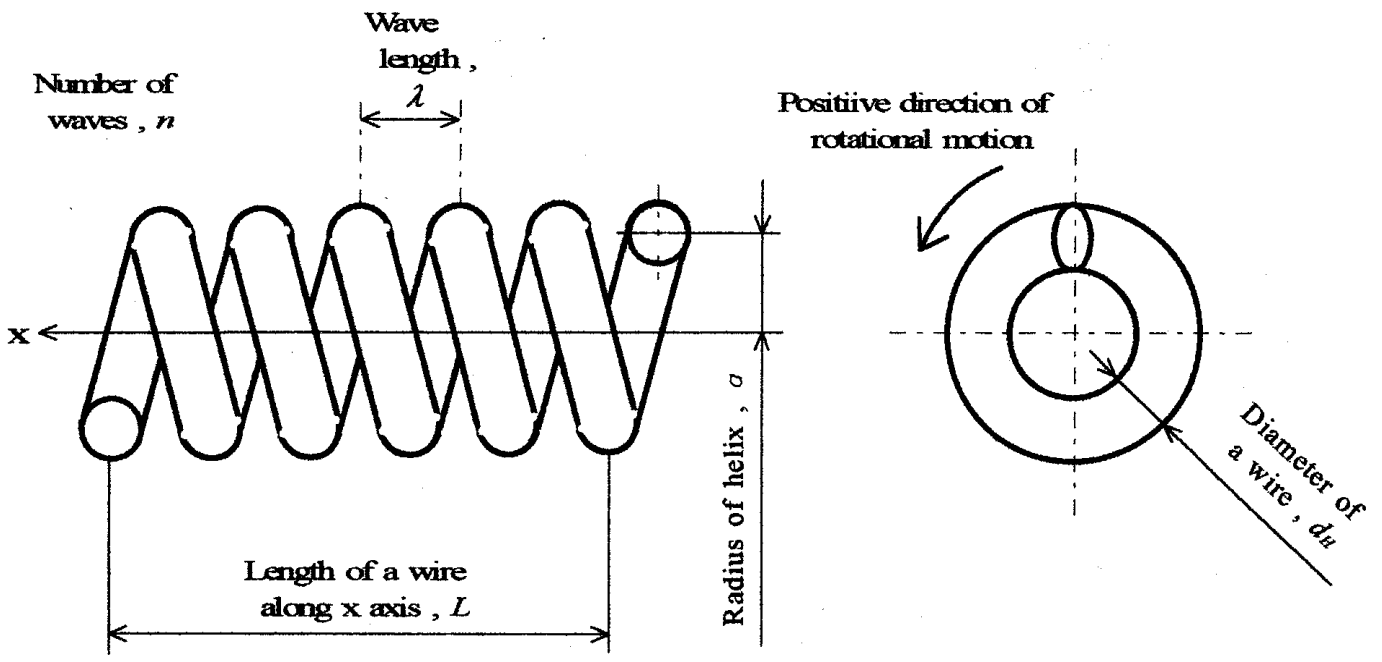

Fig.2 A helocal wire. 
$\mu$ を用いて次式で表される(4)。

$$
C_{N}=\frac{2 \pi \mu}{\ln \left(4 \lambda / d_{\mathrm{H}}\right)-1 / 2}, C_{T}=C_{N}, \gamma \approx 0.5
$$

よって、長さ $L$ 、波長 $\lambda$ の螺旋全体が発生する推力 $T$ は、式 (2)、（3）より、

$T=\int\left(-d D_{N} \sin \Theta-d D_{T} \cos \Theta\right)$

$$
\begin{aligned}
& =\frac{C_{N} \lambda f L}{\sqrt{1+(2 \pi a / \lambda)^{2}}} \frac{2 \pi a}{\lambda}\left\{\left(\frac{2 \pi a}{\lambda}\right)^{2}+\gamma\right\} \\
& =\frac{4 \pi^{2}}{\ln \left(4 \lambda / d_{\mathrm{H}}\right)-1 / 2} \frac{(2 \pi a / \lambda)^{2}+\gamma}{\sqrt{1+(2 \pi a / \lambda)^{2}}} \cdot f \cdot a \cdot L \cdot \mu
\end{aligned}
$$

式 (4)より回転螺旋が発生する推力 $T$ は、螺旋の回転 数 $f$ 、螺旋の長さ $L$ 、流体の粘性係数 $\mu$ に比例する。 また、 $f 、 L 、 \mu$ が一定の時、推力 $T$ は式（5）で 与えられる螺旋のサイズのみの関数

$G\left(a, 2 \pi a / \lambda, d_{H} / \lambda\right)$ に比例する。

$G\left(a, 2 \pi a / \lambda, d_{H} / \lambda\right) \equiv \frac{a}{\ln \left(4 \lambda / d_{H}\right)-1 / 2 \sqrt{1+(2 \pi a / \lambda)^{2}}}$

螺旋の回転数 $f$ 、螺旋の長さ $L$ 、流体の粘性係数 $\mu$ が一定の時、推力 $T$ を小さくするためには、 $a$ 、

$2 \pi a / \lambda 、 d_{H} / \lambda$ をなるたけ小さくすれば良い。逆に、 推力 $T$ を大きくするためには、 $a 、 2 \pi a / \lambda 、 d_{H} / \lambda$ をなるたけ大きくすれば良い。ただし、本解析を有効 なものとするために式（1）、および以下の幾何学的 条件(1)、(2)、モ一タの出力から課される条件(3)を満た さなければならない。

\section{幾何学的条件}

(1)螺旋波長 $\lambda$ は線径 $d_{H}$ より大きくなければならない から、

$$
d_{H} / \lambda<1
$$

この式より、 $l_{n}\left(4 \lambda / d_{H}\right)-1 / 2>0$ であるので、 $G>0$ である。よって、螺旋の回転数 $f$ と推力 $T$ の符 号は一致する。また、 $d_{H} / \lambda \approx 1$ の時、螺旋の隣り合 う部分が近づくが、本解析において蝶旋各部の流体力 学的干渉を無視していることは注意を要する（仮定 II) 。

(2)本螺旋が内径 $d_{P}$ のパイプの中に挿入されている時、 パイプの内径 $d_{P}$ は螺旋の外径 $2 a+d_{H}$ より大きいの で、

$$
2 \pi a / \lambda+\pi d_{H} / \lambda<\pi d_{P} / \lambda
$$

$2 \pi a / \lambda+\pi d_{H} / \lambda \approx \pi d_{P} / \lambda$ の時、蝶旋とパイプとが 近づくが、本解析において螺旋とパイプとの流体力学 的干涉を無視していることは注意を要する（仮定而）。

図 3 に、 $d_{H} / \lambda$ をパラメータとして、G/aと $2 \pi a / \lambda$ との関係を示す。この図に拈いて実線は $d_{P} / \lambda$ の值をパラメータとした式（8）を示している。

$$
2 \pi a / \lambda+\pi d_{H} / \lambda=\pi d_{P} / \lambda
$$

式（7）を満たすために、各実線は式（8）で示され るより左側の部分のみが意味を持つ。

モ一タの出力により課される条件

(3)螺旋を回転させるために必要なパワ $P$ は次式で与え られる。

$$
\left.P=\int\left(d D_{N} U_{N}+d D_{T} U_{T}\right)=\left\{\frac{C_{N}(2 \pi a f)^{2} L}{\sqrt{1+(2 \pi a / \lambda)^{2}}}\right\} 1+\eta\left(\frac{2 \pi a}{\lambda}\right)^{2}\right\}
$$

モータの各回転数での許容パワを $P_{0}$ とすると、

$P \leq P_{0}$ より

$$
G / a \leq \frac{P_{0}}{\mu(2 \pi a)^{3} f^{2}} \frac{\gamma+(2 \pi a / \lambda)^{2}}{1+\gamma(2 \pi a / \lambda)^{2}}
$$

$a 、 f 、 P_{0} 、 \mu$ が与えられた時、図3における各実 線仕、曲線

$$
\begin{aligned}
& G / a=\frac{P_{0}}{\mu(2 \pi a)^{3} f^{2}} \frac{\gamma+(2 \pi a / \lambda)^{2}}{1+\gamma(2 \pi a / \lambda)^{2}}=\alpha \frac{\gamma+(2 \pi a / \lambda)^{2}}{1+\gamma(2 \pi a / \lambda)^{2}} \\
& \text { (ただし、 } \left.\alpha \equiv \frac{P_{0}}{\mu(2 \pi a)^{3} f^{2}}\right) \text { より下側の部分の }
\end{aligned}
$$

みが可能な範囲になる。

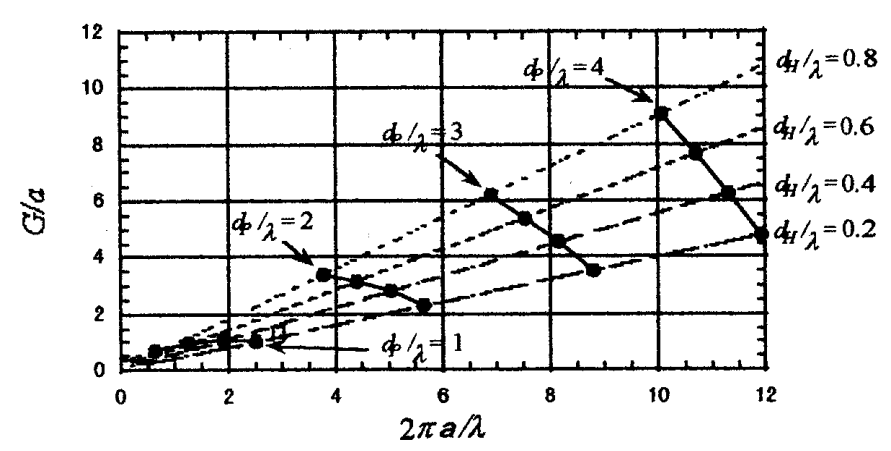

Fig. 3 Values of $G / a$, which is determined by the size of a helical wire and pipes.

図3に示した各実線のうち、(1)、(2)、(3)を満たす部 分のみが実現可能な值である。図 3 中の四角印口は、 後述する実験において用いた螺旋での値を表す。 
ヘッド

流体に働く力の釣り合いから、螺旋が発生する推力 $T$ とパイプA、Bにおける液端面に高さの差 $\boldsymbol{H}$ との 間には、以下の関係が成立する。

$$
H=T /\left(\frac{\pi}{4} \rho g d_{p}^{2}\right)
$$

式（4）、（1 1)より、

$H / y L=\frac{16 \pi}{\ln \left(4 \lambda / d_{H}\right)-1 / 2} \frac{a}{g d_{p}^{2}} \frac{(2 \pi a / \lambda)^{2}+\gamma}{\sqrt{1+(2 \pi a / \lambda)^{2}}}$

式（１２）右辺の值は、螺旋とパイプのサイズ、 $a 、$ $\lambda 、 d_{H} 、 d_{P} 、$ および重力加速度 $\mathrm{g}$ のみにより定ま る。

\section{4. 实跧結果及び考察}

図 4 K、動粘性係数 $v$ と螺旋の長さ $L$ をパラメー タとして、回転数 $f$ とへッド $H$ との関保を示す。 へッド $H$ は回転数 $f$ 、動粘性係数 $v$ 、螺旋の長さ $L$ に比例した。これは、式（1 2) で予想された関係で ある。なお、本実験の範囲では、最もレイノルズ数が 大きい場合でも $R_{e} \approx 0.2$ であり、式（1）を満足する。

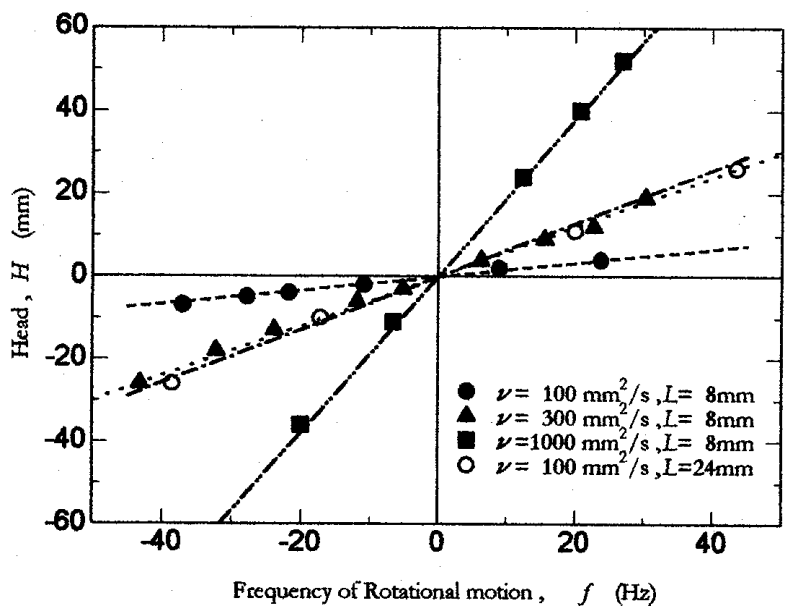

Fig.4 Relation between $f$ and $H$.

図 4 における各直線の傾き $H / f$ より、各 $v 、 L$ に 対する $H / f L v$ の值功図 5 の様に求められた。図 5 よ り、求められた $H / f L v$ の值は、動粘性俰数 $v$ 、螺旋 の長さ $L$ によらず、ほぼ一定の值 $\left(2.4 \times 10^{2} \mathrm{~s}^{2} / \mathrm{m}^{2}\right.$ 、 標準偏差 $\approx 1.4 \times 10 \mathrm{~s}^{2} / \mathrm{m}^{2}$ ) である。また、図 5 の各 点が図 4 における $f$ と $H$ との関係に基づくことから、 求められた $H / f L v$ の值は、回転数 $f$ にもよらないと

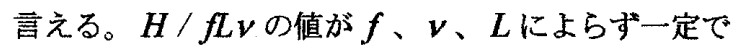
あるという結果は、理論解析の式（1 2) が示す通り である。測定によって得られた一定値は式（（1 2) で 予想された $H / f L v=1.9 \times 10^{2} s^{2} / m^{2}$ より、30\%程 度大きい值である。 $H$ の測定誤差、および式（1

2）が仮定（I）、（II）、（III）を前提にしている ことによる誤差によると考えられる。

以上の様に、H/fLvが一定值を示すという実験 結果は解析結果と定性的に一致しており、本実験結果 は前章で示した抵抗力理論に基づく解析で説明できる と言える。また、本実験においては、螺旋の回転数を 変化させることによって、 $T=\rho g\left(\pi / 4 d_{P}{ }^{2}\right) H \approx 10^{-5}$ $\sim 10^{-3} N$ 程度における流体駆動力を制御することが できたが、螺颃のサイズを変えることにより、さらに 幅広い範囲での流体駆動力の制御が可能である。

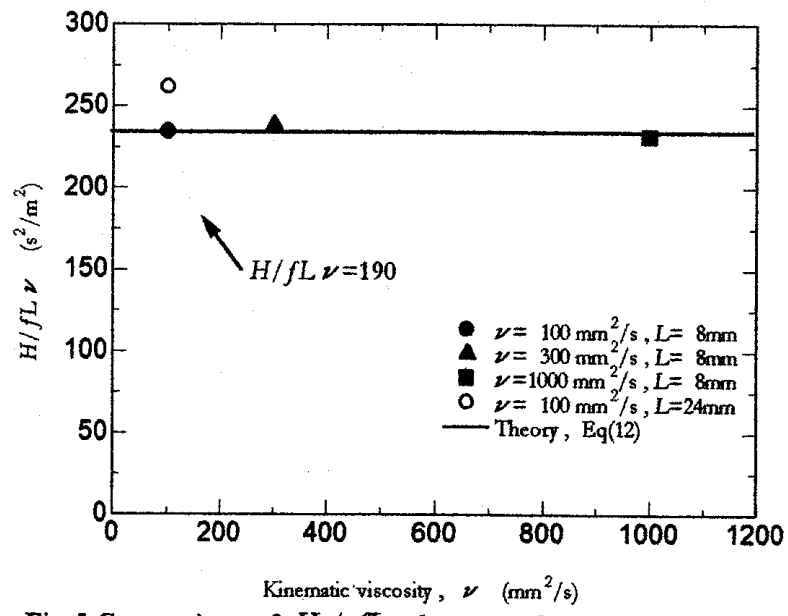

Fig.5 Comparison of $H / f L v$ between the experimental values and theoretical one.

また、本実験にお订る螺旋のサイズ、螺旋の回転数、 パイプの内径を一定にした場合、ヘッド $H$ が流体の 動粘性係数 $\boldsymbol{v}$ に比例することを用いて、本実験装置は 大量の試験流体を必要としない小型粘度計としての使 用が可能である。図 6 に回転螺旋による小型粘度計の 例を示す。本粘度計の使用方法は以下の通りである。

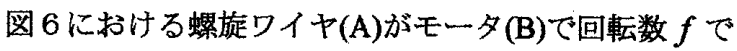
回転する。流体中に、流路口(C)を液面線(D)までつけ る。回転螺旋によって流体が分岐流路(E)内に引き上 げられるが、引き上げられた液体の端面(F)と液面線 (D)との高さの差 $H$ を目盛り(G)で読む。この作業を、 
動粘性保数が既知、未知である液体について行う。式 (13) より、

$$
\begin{aligned}
v & =\frac{H}{f L} \frac{\ln \left(4 \lambda / d_{H}\right)-1 / 2}{16 \pi} \frac{g d_{p}^{2}}{a} \frac{\sqrt{1+(2 \pi a / \lambda)^{2}}}{(2 \pi a / \lambda)^{2}+\gamma} \\
& \equiv \frac{H}{f} K
\end{aligned}
$$

$K$ は、螺旋のサイズ、パイプ直径で決まる值である が、本式を導出するにあたっては、前章で述べた仮定 （I）、（II）、（II）を含むので、動粘性保数が既 知である液体について $H$ の測定を行い $K=\frac{f v}{H}$ を用 いて決定する。ちなみに、表に示した螺旋 $(L=8 \mathrm{~mm})$ 、パイプを用いた場合、図5で示され た $L=8 \mathrm{~mm}$ の場合の黒印の平均值 $H / f L v \approx 2.4 \times 10^{2} s^{2} / m^{2}$ より、

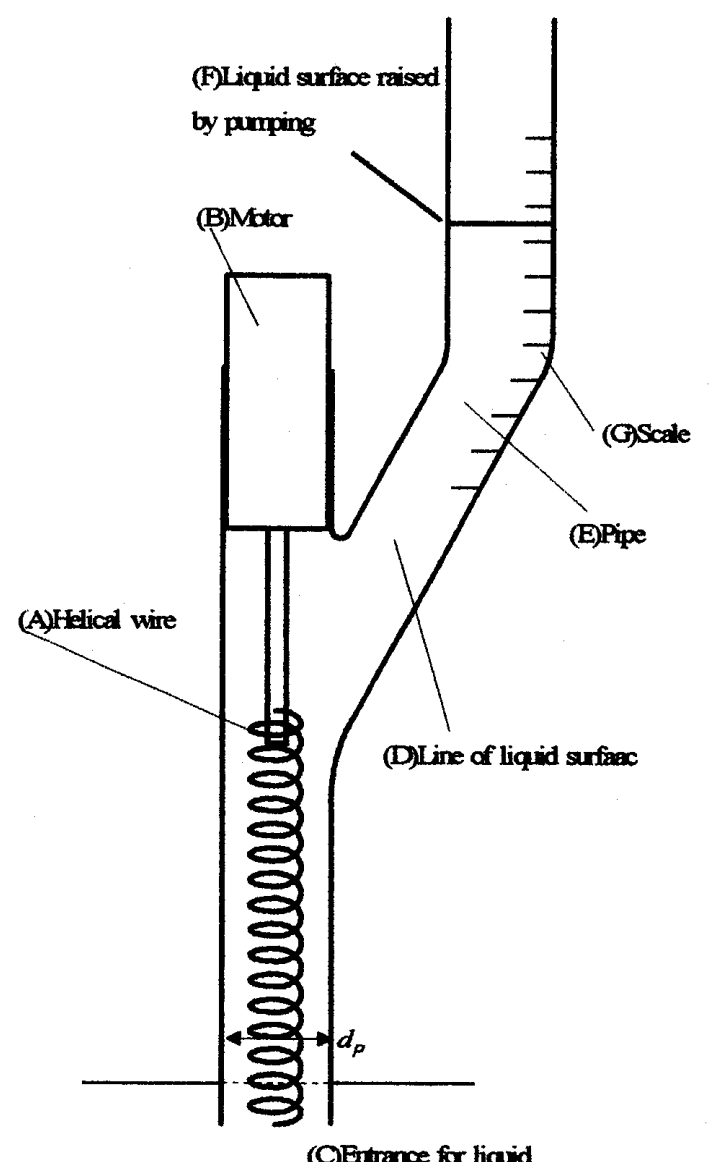

(C)Etrance far biqud
$\left.K=1 /\left(2.4 \times 10^{2} \mathrm{~s}^{2} / \mathrm{m}^{2}\right) \times L\right\}=0.5 \mathrm{~m} / \mathrm{s}^{2}$ である。決 定された $K$ 、動粘性係数が末知である液体での測定 值 $H$ 、式（1 3 $)$ を用いて動粘性係数 $v$ が得られる。

本粘度計よりも少量の試料流体で測定可能な粘度計 にコーンプレート粘度計があるが、本粘度計はコーン プレート粘度計よりも以下の 2 点で優れている。(1) コーンプレート粘度計は、トルク計を必要とするため 高価である。(2)本粘度計を用いた場合、容器から試験 流体を取り出さずに粘度を測定することが可能であり、 本粘度計を容器内の試験流体に浸したままにすること で、粘度の常時モニタリングが可能である。一方、 コーンプレート粘度計を用いる場合には容器より試験 流体を汲み出し、粘度計内に注入する必要がある。

\section{5. 結雷}

（1）回転螺旋を用いた小型ポンプを武作し、螺旋の 回転数と流体駆動力 (ヘッド) との間の線形性を確認 した。このことにより、高い精度での流体駆動力 (ヘッド）の制御が可能である。

（2）本小型ポンプは、流体の粘性係数と流体駆動力 (ヘッド）との間にも線形関係が碓認されたので、小 型の粘度計としても利用できる ${ }^{(5)}$ 。

（3）細菌の運動の解析において用いられる低レイノ ルズ数における抵抗力理論 ${ }^{(4)}$ が、本小型ポンプの性 能推算に掞いても有効であることが確㑇された。

本研究は、科学振興調整費流動促進研究制度、科学 技術振興事業団計算科学推進事業の研究課題として行 われたものの一部である。ここに記して感謝の意を表 する。

\section{文献}

（1）例えば、日本機械学会糄：機械工学便覧基礎編. A 5 流体工学 (1986).

(2) Azuma,A.: The biokinetics of flying and swimming, Springer-Verlag.(1992).

(3) 加藤直三: アクアバイオメカニズムに関する研 究動向, 日本造船学会誌, 830, 54(1998), 544-551.

(4) 例えは匚、Gray,J. and Hancock,G.J., The propulsion of seaurchin spermatozoa, J.exp. Biol. 32 (1955), 802-814.

（5）砂田茂、尾崎浩一、田中誠、安田邦男：回転微 小式粘度計、特願 2000-143075.

Fig.6 Viscometer with a rotating helical wire 